\title{
SPECIFIC FEATURES OF THE ARTERIAL VASCULARIZATION IN THE HEART UNDER NORMAL CONDITIONS AND IN MYOCARDIAL INFARCTION
}

\author{
Lezhnina O. Yu., Korobkeyev A. A.
}

\section{Stavropol State Medical University, Russian Federation}

AS of today in Russia, the circulatory system diseases rank first in the overall morbidity patterns, accounting for $\mathbf{1 8 . 8} \%$. Coronary artery disease, including myocardial infarction, alongside with cerebrovascular diseases and essential hypertension are among the most common cardiovascular ailments [6].

There have been numerous studies carried in relation to the morphology of the human heart arterial vascularization [3], its venous angioarchitecture [1], and the mutual dimensional orientation of subepicardial vessels [5]. However, we still lack comparative data on coronary angioarchitecture in the heart under normal conditions and in case of myocardial infarction. This study was performed to bridge the above-mentioned gap in the currently available knowledge.

Objective: our purpose here is to present the morphofunctional parameters pertinent to the arterial vascularization morphology in the heart both in the absence of coronary circulation disturbances and in anteroseptal myocardial infarction in humans in their second period of adulthood with right coronary pattern of the coronary arteries branching.

Material and Methods. Subepicardial branchings were studied in the anterior interventricular branch (AIVB) of left coronary artery in 10 hearts as well as 12 lifetime coronarographies in humans in their second period of adulthood with right coronary pattern of the coronary arteries branching under normal conditions and in anteroseptal myocardial infarction. During angiography the heart vessels were injected with lead oxide dissolved in glycerin (in equal proportions). For histological examination vasculature samples were taken followed by their cross-sections preparation and hematoxylin and eosin staining.

The morphometric measuring of the vessels length, their inner and outer diameters, and cross-sectional areas was carried out using appropriate software (VideoTest-Morphology, 5.0; Makhaon). The original computer programs allowed

Lezhnina Oksana, PhD; Associate Professor, Department of Anatomy, Stavropol State Medical University:

tel.: (8652)353229; e-mail: okliz26@mail.ru

Korobkeyev Alexander, MD, PhD, Professor; Head of Department of Anatomy, Stavropol State Medical University;

tel.: (8652)353229; e-mail: Korobkeev@Stgma.ru establishing new morphofunctional parameters for coronary vascularization (among them constriction coefficients $(\mathrm{Cc})$ and dilatation coefficients $(\mathrm{Cd})$ related to the net luminal diameter of the arterial bed; the share of the net longitudinal section of the arterial vasculature in the total area of the vascularized surface, and the average distance between the branchings) [2].

The statistical analysis of the results obtained was carried out through the variation method using the data analysis package pertaining to the Excel Windows Office XP and Statistica 6.0 software with the arithmetical mean and standard error $(\mathrm{M} \pm \mathrm{m})$ calculation. Student's t-test for independent samples was also performed [4].

Results and Discussion. The net luminal area ( $\Sigma$ Slum) of the AIVB in the absence of coronary circulation disturbances was found to prevail over its values in case of myocardial infarction, amounting to $15.2 \pm 1.5 \mathrm{~mm}^{2}$ and $9.6 \pm 1.1 \mathrm{~mm}^{2}$, respectively.

Normally in the upper third of the anterior interventricular sulcus (AIVS) the $\Sigma$ Slum of the AIVB branches generally tends to decrease, yet increasing slightly to $15.4 \pm 1.5 \mathrm{~mm}^{2}$ in its medium third. A significant 4.2 -fold $\left(2.3 \pm 0.9 \mathrm{~mm}^{2}\right)$ reduction in the net luminal area of the AIVB derivatives was found in the initial segments of the AIVS upper third in myocardial infarction.

Coronary circulation pathology is associated with a pronounced decrease in the net luminal area of the AIVB derivatives from $19.5 \pm 1.8 \mathrm{~mm}^{2}$ to $8.8 \pm 0.9 \mathrm{~mm}^{2}$ in a $26.2 \pm 1.5 \mathrm{~mm}$ long segment of the vessel found in the middle of the AIVS upper third. Increased $\Sigma$ Slum of the AIVB branches in the medium and terminal parts of the AIVS upper third (up to $19.5 \pm 1.8 \mathrm{~mm}^{2}$ and $18.6 \pm 1.3 \mathrm{~mm}^{2}$, respectively) is a common finding in myocardial infarction as well.

The charts demonstrating the alteration in the AIVB net luminal area for all objects reveal a general trend for this value to decrease along the medium and lower third of the AIVB before the subepicardial vessel branches penetrate the myocardium. However, the medium third of the AIVS, both in the normal condition and in case of myocardial infarction, show a prominent increase in the $\Sigma$ Slum in the AIVB (by 1.6 times - from $4.3 \pm 0.8 \mathrm{~mm}^{2}$ to $6.8 \pm 0.9 \mathrm{~mm}^{2}$, and 1.4 times from $7.6 \pm 0.5 \mathrm{~mm}^{2}$ up to $10.6 \pm 1.1$ $\mathrm{mm}^{2}$ respectively).

An analysis of the data obtained showed that the 
hearts with no coronary circulation disturbances had zero $\mathrm{Cc}$ values through a significant area in the upper third of the AIVS with its values increasing gradually in the medium and lower third. And at the initial segment of the AIVS lower third only the $\mathrm{Cc}$ of the AIVB derivates showed a single decrease from $0.70 \pm 0.01$ to $0.50 \pm 0.01$. Those with myocardial infarction typically demonstrate a maximum increase in the AIVB $C_{C}$ in the initial segment of the AIVS upper third up to $0.80 \pm 0.01$ followed by an intense fall down to zero values. A significant jump-like increase in the AIVB Cc in pathologies (up to $0.20 \pm 0.01$ ) and decrease down to zero were detected in the initial parts of the AIVS medium third. In the lower parts of the AIVS, the Cc increases gradually up until the AIVB subepicardial vessel branches penetrate the myocardium.

The study of the $\mathrm{Cd}$ in the AIVB derivates through the AIVS showed that when in normal condition this value is at zero while increasing slightly up to $0.010 \pm 0.005$ in the initial part of its upper third. Yet, in case of myocardial infarction the Cd demonstrates an intensive jump-like change revealing a double increase in the parameter in the AIVS upper third, up to $1.02 \pm 0.11$ and $0.90 \pm 0.03$ respectively. Zero

\section{References}

1. Korobkeyev A. A., Nikolenko V. N., Lezhnina O. Yu. et al. Morphofunctional structure of venous subepicardial vascularization in human heart - age-related aspect. Stavropol; 2012. $176 \mathrm{p}$.

2. Lezhnina O. Yu., Korobkeyev A. A., Fedko I. I. Modern morphofunctional parameters in heart arterial bed. Astrakhan Medical Journal. 2012;4:166-168.

3. Lezhnina O. Yu., Korobkeyev A. A. Anatomic-functional features of heart coronary bed based on lifetime coronarographies. Medical News of North Caucasus. 2013;8(1):73-75.

\section{SPECIFIC FEATURES OF THE ARTERIAL}

VASCULARIZATION IN THE HEART UNDER NORMAL CONDITIONS AND IN MYOCARDIAL INFARCTION

LEZHNINA O. Y., KOROBKEYEV A. A.

Subepicardial branchings were studied in the anteriorinterventricularbranch ofleftcoronaryartery in 10 hearts as well as 12 lifetime coronarographies in humans in their second period of adulthood with right coronary pattern of the coronary arteries branching under normal conditions and in anteroseptal myocardial infarction.

The represented structural and functional organization of subepicardial arterial bed of the heart in norm and at myocardial infarction characterizes vascularization features of different topographic parts of the organ.

Key words: coronary arteries, structural and functional organization, morphofunctional parameters, myocardial infarction, right coronary pattern of the coronary arteries branching, second period of adulthood values of the AIVB Cd in pathologies were detected through the AIVS medium and lower third up until the arterial branches enter the myocardium.

A comparative analysis of the net longitudinal section of the arterial vasculature in the total area of the vascularized hear surface produced similar values in this parameter, namely $0.017 \pm 0.001$ in all those involved in the study.

The distance between the AIVB branchings is normally $93.8 \pm 1.5 \mathrm{~mm}$. However, in myocardial infarction in the anterior surface of the heart this index goes down significantly constituting $37.9 \pm 1.2$ $\mathrm{mm}$.

Conclusion. The comparative analysis of the morphofunctional parameters pertinent to the arterial bed morphology in the heart both in the absence of coronary circulation disturbances and in anteroseptal myocardial infarction serves a description of the angioarchitecture in the coronary vascularization in norm and pathology; it also makes it possible to draw certain conclusions regarding the vascularization intensity in various parts of the organ in humans in their second period of adulthood with right coronary pattern of the coronary arteries branching.

4. Rebrova O.Yu. Statistical analysis of medical data. Using software package STATISTICA. M.: «MediaSfera»; 2006. $312 \mathrm{p}$.

5. Fedko I. I., Lezhnina O. Yu., Korobkeyev A. A. Morphofunctional description of topography-anatomic relations between arteries and heart veins. Medical News of North Caucasus. 2013;8(2):60-62.

6. Shalnova S. A., Konradi A. O., Karpov Yu. A., Kontsevaya A. V. et al. Analysis of death rate from cardiovascular diseases in 12 regions of Russia involved in the study cardiovascular disease epidemiology in various regions of Russia. Russian Cardiology Journal. 2012;5:6-11.

\section{ОСОБЕННОСТИ АРТЕРИААЬНОГО PУСАА СЕРАЦА В HOPME \\ И ПРИ ИНФАРКТЕ МИОКАРАА \\ О. Ю. АЕЖНИНА, А. А. КОРОБКЕЕВ}

Исследованы субэпикардиальные разветвления передней межжелудочковой ветви левой венечной артерии 10 сердец и 12 прижизненных коронароангиографий людей второго периода зрелого возраста с правовенечным вариантом ветвления венечных артерий в норме и с передне-перегородочным инфарктом миокарда.

Представленная структурно-функциональная организация субэпикардиального артериального русла сердца в норме и при инфаркте миокарда характеризует особенности васкуляризации различных топографических отделов органа.

Ключевые слова: венечные артерии, структурно-функциональная организация, морфофункциональные параметры, инфаркт миокарда, правовенечный вариант ветвления венечных артерий, второй период зрелого возраста 